\title{
Penta-Coordinated Complexes of Bis(2,4-pentanedionato) Copper(II) with Some Oxygen Donor Organic Solvents
}

\author{
B. P. Baranwal*, G. K. Parashar, and R. C. Mehrotra \\ Department of Chemistry, University of Delhi, Delhi-110007, India
}

Z. Naturforsch. 36 b, 42-44 (1981); received June 30, 1980

Bis(2,4-pentanedionato) Copper(II) Complexes, ER Spectra, Magnetic Moments, IR Spectra

Bis(2,4-pentanedionato) Copper(II) reacts with some oxygen donor organic solvents to form addition complexes with general formula, $\mathrm{Cu}(2,4$-pentanedionato) 2 . $\mathrm{L}$ (where $\mathrm{L}=$ $\mathrm{MeOH}$, EtOH, $\mathrm{Pr}^{i} \mathrm{OH}, \mathrm{Bu}^{t} \mathrm{OH}$, THF, MeCOMe, MeCOEt and MeCOPr ${ }^{n}$ ). The complexes were recrystallized and characterized by the elemental analyses, infrared and electronic spectra, molecular weight and magnetic measurements.

Acetylacetonates of a number of transition metals (e.g., chromium, iron, cobalt, nickel, copper and zinc) have been widely investigated $[1,2]$ for their various physical and structural properties. Considerable attention seems to have been directed to the addition complexes of copper bis-acetylacetonate with a number of nitrogen donor ligands [3-5] but the addition complexes of $\mathrm{Cu}(\mathrm{acac})_{2}$ with oxygen donor ligands have not been reported so far. The present paper describes the preparation and characterization of a few addition complexes of copper bis-acetyl-acetonate with some oxygen donor ligands. A plausible geometry of these derivatives is proposed on the basis of various spectral and magnetic studies and molecular weight determinations.

\section{Experimental}

Throughout these investigations, precautions were taken to exclude moisture. Alcohols and other solvents were dried by the usual literature procedures [6]. Copper was estimated iodometrically [7] and alcohols by an oxidimetric method [8] after removing them azeotropically with benzene.

Visible reflectance spectra of these complexes were recorded in nujol mull on a Russian CØ-10 recording spectrophotometer and in chloroform solution, on a Beckman model-26 spectrophotometer. The infrared spectra in the range 4000 to $400 \mathrm{~cm}^{-1}$ were recorded on a Perkin-Elmer $735 \mathrm{~B}$ infrared spectrophotometer using Nujol mulls. Magnetic susceptibilities were measured at the room temperature by standard Gouy method in chloroform solutions. Molecular weights were determined with a semi-micro ebulliometer (Gallenkamp) using a thermistor sensing device.

* Reprint requests to Dr. B. P. Baranwal. 0340-5087/81/0100-0042/\$01.00/0

\section{Preparation of compounds}

Copper bis-acetylacetonate was prepared by the standard method described in the literature [1]. Weighed amounts of copper bis-acetylacetonate were treated with excess of oxygen donor ligands. The reaction mixtures were refluxed for nearly 2-3 h, when $\mathrm{Cu}(\mathrm{acac})_{2}$ dissolved giving clear greenish blue solutions. After keeping the solution overnight at the room temperature blue-needles were crystallized which were washed with $n$-hexane and finally dried under reduced pressure $(1 \mathrm{~mm})$ at the room temperature. Results are summarized in Table I.

\section{Results and Discussion}

Solvolytic reactions of copper bis-acetylacetonate in excess of oxygen donor solvents under refluxing conditions lead to the formation of the complexes of the type $\mathrm{Cu}(\mathrm{acac})_{2} \cdot \mathrm{L}$ (where $\mathrm{L}=\mathrm{MeOH}$, $\mathrm{EtOH}$, $\mathrm{Pr}^{i} \mathrm{OH}, \mathrm{Bu}^{t} \mathrm{OH}$, THF, MeCOMe, MeCOEt and $\mathrm{MeCOPr}^{n}$ ). Addition complexes formed in the solutions were crystallized as blue crystalline solids which were washed with $n$-hexane and dried in vacuo. These adducts are soluble in the parent solvents as well as in common organic solvents such as benzene, chloroform and dichloromethane. All the complexes have been characterised by elemental analyses and molecular weight determinations in refluxing chloroform, in which they show monomeric behaviour.

Copper acetylacetonate monoethanolate appears to be stable up to $70^{\circ} \mathrm{C}(2 \mathrm{~mm})$, and on further heating it loses about 0.5 molecule of ethanol at $90-100^{\circ} \mathrm{C}$. Finally heating to a temperature $\sim 120^{\circ} \mathrm{C}(2 \mathrm{~mm})$ is required to remove the remaining alcohol from the adduct. A similar pattern of loss of the adduct molecule has been found with the complexes of copper acetylacetonate with tetrahydrofuran, isopropanol and methyl-ethyl ketone. 
Table I. Adducts of Bis(2,4-pentanedionato) copper(II) with some oxygen donor ligands.

\begin{tabular}{|c|c|c|c|c|c|}
\hline & Reactants & Product* & $\begin{array}{l}\text { Analyses [\%] } \\
\text { copper }\end{array}$ & $\begin{array}{l}\text { found(calcd.) } \\
\text { alcohol }\end{array}$ & $\begin{array}{l}\text { Mol. Wt.** } \\
\text { found(calcd.) }\end{array}$ \\
\hline 1. & $\mathrm{Cu}(\text { acac })_{2}+\mathrm{MeOH}$ & $\mathrm{Cu}(\text { acac })_{2} \cdot \mathrm{MeOH}$ & $21.43(21.62)$ & - & $281(294)$ \\
\hline 2. & $\mathrm{Cu}(\text { acac })_{2}+\mathrm{EtOH}$ & $\mathrm{Cu}(\text { acac })_{2} \cdot \mathrm{EtOH}$ & $20.52(20.64)$ & $14.84(14.97)$ & $298(308)$ \\
\hline 3. & $\mathrm{Cu}(\text { acac })_{2}+\mathrm{Pr}^{i} \mathrm{OH}$ & $\mathrm{Cu}(\mathrm{acac})_{2} \cdot \mathrm{Pr}^{i} \mathrm{OH}$ & $19.58(19.74)$ & $18.60(18.67)$ & $341(322)$ \\
\hline 4. & $\mathrm{Cu}(\mathrm{acac})_{2}+\mathrm{Bu}^{t} \mathrm{OH}$ & $\mathrm{Cu}(\mathrm{acac})_{2} \cdot \mathrm{Bu}^{t} \mathrm{OH}$ & $18.70(18.92)$ & - & $327(336)$ \\
\hline 5. & $\mathrm{Cu}(\mathrm{acac})_{2}+\mathrm{THF}$ & $\mathrm{Cu}(\mathrm{acac})_{2} \cdot \mathrm{THF}$ & $18.71(19.04)$ & - & $345(334)$ \\
\hline 6. & $\mathrm{Cu}(\mathrm{acac})_{2}+$ Acetone & $\mathrm{Cu}(\mathrm{acac})_{2} \cdot \mathrm{MeCOM} \Theta$ & $19.86(19.87)$ & - & $304(320)$ \\
\hline 7. & $\mathrm{Cu}(\mathrm{acac})_{2}+\underset{\mathrm{Et}}{\mathrm{M} \oslash}>\mathrm{CO}$ & $\mathrm{Cu}(\text { acac })_{2} \cdot \mathrm{MeCOEt}$ & $19.62(19.75)$ & - & $316(334)$ \\
\hline 8. & $\mathrm{Cu}(\text { acac })_{2}+\underset{\operatorname{Pr}^{n}}{\mathrm{Me}} \succ \mathrm{CO}$ & $\mathrm{Cu}(\text { acac })_{2} \cdot \mathrm{MeCOPr}^{n}$ & $18.23(18.27)$ & - & $340(348)$ \\
\hline
\end{tabular}

* Blue crystalline solid; ** in refluxing chloroform.

\section{Structural features}

Infrared spectra of all the complexes have been recorded in the range $4000-400 \mathrm{~cm}^{-1}$. A broad and strong absorption band observed at $\sim 3150 \mathrm{~cm}^{-1}$ in the alcoholate complexes may be assigned to $v(\mathrm{OH})$ vibrations. In pure alcohols, this band appears at $\sim 3300 \mathrm{~cm}^{-1}[9]$ and the lowering can be understood to arise from the coordination of the alcohol molecule to the central copper atom. In the spectrum of $\mathrm{Cu}(\text { acac })_{2} \cdot \mathrm{THF}$, the band at $\sim 1050 \mathrm{~cm}^{-1}$ is attributed to $\nu \mathrm{C}-\mathrm{O}-\mathrm{C}$ vibration of tetrahydrofuran which appears at $1075 \mathrm{~cm}^{-1}$ in the ligand itself. This band does not appear in the spectra of the addition complexes with other ligands.

Electronic reflectance spectra of the solid complexes of copper(II) show a broad absorption in the visible region with two maxima near 15,500 and $18,500 \mathrm{~cm}^{-1}$. Assignments of these absorption bands to appropriate $d-d$ transitions continues to be a subject of great interest and considerable controversy [10-12]. It has been observed that the solu- tion spectra of all the present complexes in nondonor solvents are almost identical with the reflectance spectra. The positions of the observed absorption maxima and the proposed assignments are summarized in Table II. These are the characteristic ${ }^{2} \mathrm{~B}_{1} \rightarrow{ }^{2} \mathrm{~A}_{1}$ and ${ }^{2} \mathrm{~B}_{1} \rightarrow{ }^{2} \mathrm{E}$ absorptions of the copper(II) ion ( $\mathrm{d}^{9}$ system) in a square pyramidal environment [13]. A similar spectrum has been observed in the case of $\mathrm{Cu}(\mathrm{acac})_{2} \cdot$ quinoline [5] which supports a five-coordinated configuration for these complexes also.

Magnetic moments also serve as useful criteria for differentiating square pyramidal complexes of copper(II) from other geometries. In view of the low symmetry of square pyramidal complexes, the magnetic moments are expected to be fairly close to the spin-only value (1.73 B.M.). All the present complexes show, at room temperature, magnetic moments in the range 1.74 to $1.81 \mathrm{~B} . \mathrm{M}$. [14]. These values are quite close to the spin-only value for a $\mathrm{d}^{9}$ system.

\begin{tabular}{lllll}
\hline & Compound & ${ }^{2} \mathrm{~B}_{1 \mathrm{~g}} \rightarrow{ }^{2} \mathrm{~A}_{1 \mathrm{~g}}$ & ${ }^{2} \mathrm{~B}_{1 \mathrm{~g}} \rightarrow{ }^{2} \mathrm{E}_{\mathrm{g}}$ & $\mu_{\text {eff }}$ (B.M.) \\
\hline 1. $\mathrm{Cu}(\mathrm{acac})_{2} \cdot \mathrm{MeOH}$ & 15,150 & 19,050 & 1.78 \\
2. $\mathrm{Cu}(\mathrm{acac})_{2} \cdot \mathrm{EtOH}$ & 15,385 & 18,620 & 1.75 \\
3. $\mathrm{Cu}(\mathrm{acac})_{2} \cdot \mathrm{Pr}^{i} \mathrm{OH}$ & 15,267 & 18,870 & 1.79 \\
4. $\mathrm{Cu}(\mathrm{acac})_{2} \cdot \mathrm{Bu}^{t} \mathrm{OH}$ & 15,267 & 18,350 & 1.81 \\
5. $\mathrm{Cu}(\mathrm{acac})_{2} \cdot \mathrm{THF}$ & 15,150 & 19,050 & 1.79 \\
6. $\mathrm{Cu}(\mathrm{acac})_{2} \cdot \mathrm{MeCOM} \Theta$ & 15,267 & 18,520 & 1.77 \\
7. $\mathrm{Cu}(\mathrm{acac})_{2} \cdot \mathrm{MeCOEt}$ & 15,150 & 18,520 & 1.79 \\
8. $\mathrm{Cu}(\mathrm{acac})_{2} \cdot \mathrm{MeCOPr} n$ & 15,285 & 18,690 & 1.74 \\
\hline
\end{tabular}

Table II. Electronic spectra* and magnetic moments of adducts of $\operatorname{bis}(2,4$. pentanedionato) copper(II).

* Transitions in $\mathrm{cm}^{-1}$. 
[1] J. P. Fackler (Jr.), Prog. Inorg. Chem. 7, 361 (1966).

[2] R. C. Mehrotra, D. P. Gaur, and R. Bohra, Chemistry of Metal $\beta$-Diketonates, Academic Press, England 1978.

[3] S. Ooi and Q. Fernando, Chem. Commun. 1967, 532.

[4] P. Jose, S. Ooi, and Q. Fernando, J. Inorg. Nucl. Chem. 31, 1971 (1969).

[5] D. P. Graddon, Coord. Chem. Rev. 4, 1 (1969).

[6] R. C. Mehrotra, G. Srivastava, and D. P. Gaur, J. Organomet. Chem. 63, 221 (1973).

[7] H. H. Willard, N. H. Furman, and C. E. Bricker, Elements of Quantitative Analysis, p. 266, Van Nostrand, Princeton 1956.
[8] D. C. Bradley, F. M. A. Halim, and W. Wardlaw, J. Chem. Soc. 1950, 3450.

[9] L. J. Bellamy, The Infrared Spectra of Complex Molecules, Chapman and Hall, London 1975.

[10] F. A. Cotton and J. J. Wise, J. Am. Chem. Soc. 88, 3451 (1966).

[11] F. A. Cotton and J. J. Wise, Inorg. Chem. 6, 915 (1967).

[12] D. N. Sen and N. Thankarajan, Indian J. Chem. 6, 746 (1968).

[13] L. F. Lindoy, N. E. Tokel, L. B. Anderson, and D. H. Busch, J. Coord. Chem. 1, 7 (1971).

[14] B. N. Figgis, Introduction to Ligand Fields, p. 315-321, Wiley Eastern Limited, 1976. 